\title{
CUIDADO PSICOLÓGICO ON-LINE OFERTADO NO CONTEXTO DE PANDEMIA PELO PROGRAMA ACOLHER DA UNIVERSIDADE DO EXTREMO SUL CATARINENSE
}

Tamires Rosa Pacheco

Dipaula Minotto da Silva

DOI: http://dx.doi.org/10.18616/intcov30

Em 22 de janeiro de 2020, foi ativado o Centro de Operações de Emergências em Saúde Pública para o novo coronavírus (covid-19), pois uma pandemia estava ocorrendo e, no Brasil, já existiam casos suspeitos (BRASIL, 2020). Os impactos psicológicos e sociais nas emergências podem deteriorar a saúde mental e o bem-estar psicossocial da população afetada a longo prazo, ameaçando a paz, os Direitos Humanos e o desenvolvimento (INTERAGENCY STANDING COMMITTEE, 2007).

No dia 20 de março 2020, o Conselho Federal de Psicologia (CFP) publicou diretrizes para a atuação dos psicólogos diante da pandemia, orientando a categoria a seguir rigorosamente as recomendações e protocolos obrigatórios emanados pela Organização Mundial da Saúde (OMS). Foi indicada aos profissionais a realização de atendimentos via tecnologias de comunicação à distância (chamadas de vídeo, telefone, mensagens de texto).

O programa de atenção aos estudantes da Universidade do Extremo Sul Catarinense (UNESC), o Programa Acolher, visa cuidar da saúde psicológica/emocional dos estudantes, buscando em suas ações a promoção e prevenção sofrimento mental, sendo um espaço de escuta, acolhida e cuidado com a vida. Tem o objetivo de auxiliar o acadêmico a refletir sobre seu percurso de vida, reconhecendo suas potencialidades, planejando seu futuro e desenvolvendo habilidades emocionais necessárias para lidar com as realidades pessoal, familiar e social. Realiza acolhimentos, escuta qualificada, psicoterapia breve individual, práticas integrativas e complementares em grupos, além de grupos terapêuticos, psicoterapêuticos e operativos. 
Nesse novo cenário, o Programa Acolher manteve seus atendimentos seguindo as orientações do CFP e da OMS, sendo assim suas atividades foram reinventadas e adaptadas às necessidades do contexto, com atendimentos on-line. Os atendimentos estão sendo realizados por meio do aplicativo Google Meet, chamadas de vídeo pelo WhatsApp ou de forma escrita também via WhatsApp.

Os tipos mais comuns de queixas apresentadas pelos acadêmicos se referem a: medo de contaminação por covid-19, extensão da quarentena em decorrência de comportamentos inadequados de pessoas da comunidade; dificuldade em fazer a psicoterapia em casa pela falta de privacidade; medo de não conseguir concluir a graduação no período planejado; adiamento da festa de formatura; preocupação com as aulas práticas e os estágios obrigatórios; dificuldade de adaptação ao novo formato de aulas, mediadas por tecnologia; instabilidade financeira; mudanças bruscas na rotina; medo e fragilidades diante do desconhecido; isolamento; frustração e improdutividade. Alguns acadêmicos não aceitaram a psicoterapia on-line de início, mas depois procuraram o Programa aderindo à nova proposta de atendimento.

O apoio psicológico neste período foi e está sendo fundamental, pois além das questões que fizeram estudantes procurar ou ser encaminhados para o programa antes da pandemia, o novo cenário intensificou e gerou novos sofrimentos.

\section{REFERÊNCIAS}

BRASIL. Ministério da Saúde. Secretaria de Vigilância em Saúde. Boletim Epidemiológico: situação epidemiológica da febre amarela no monitoramento 2019/2020. vol. 2. Brasília, DF: Ministério da Saúde, jan. 2020. n. 1.

INTER-AGENCY STANDING COMMITTEE. Comitê Permanente Interagências (IASC). Diretrizes do IASC sobre saúde mental e apoio psicossocial em emergências humanitárias. Tradução de Márcio Gagliato. Genebra: IASC, 2007. 